Check for updates

Cite this: RSC Adv., 2019, 9, 23908

\title{
Aqueous leaching of lithium from simulated pyrometallurgical slag by sodium sulfate roasting $\dagger$
}

\author{
Na Li, ${ }^{a}$ Jiahui Guo, ${ }^{a}$ Zhidong Chang, (D) *a Hui Dang, ${ }^{a}$ Xin Zhao, ${ }^{a}$ Shujaat Ali, ${ }^{\text {b }}$ \\ Wenjun Li, (D) a Hualei Zhou ${ }^{\mathrm{a}}$ and Changyan Sun ${ }^{\mathrm{a}}$
}

In the pyrometallurgical treatment for spent lithium-ion batteries (LIBs), lithium is generally present in slag with $\mathrm{Al}, \mathrm{Ca}$ and $\mathrm{Si}$ and is hard to be further treated. In this study, lithium was recovered from a simulated pyrometallurgical slag (pyro-slag) via sodium roasting and water leaching. The thermodynamic process for the reactions between slag and additives such as $\mathrm{NaCl}, \mathrm{NaNO}_{3}$ and $\mathrm{Na}_{2} \mathrm{SO}_{4}$ were simulated during roasting by the $\mathrm{HSC}$ software, where $\mathrm{Na}_{2} \mathrm{SO}_{4}$ possessed stronger chemical reactivity. The optimal conditions for roasting were experimentally determined to be $800{ }^{\circ} \mathrm{C}$ for $60 \mathrm{~min}$ and an $\mathrm{Na}_{2} \mathrm{SO}_{4} / \mathrm{Li}$ molar ratio of $3: 1$, followed by water leaching at $70{ }^{\circ} \mathrm{C}$ for $80 \mathrm{~min}$ using a liquid-to-solid (L/S) mass ratio of $30: 1$. This yielded a maximum of $93.62 \%$ lithium recovery. The mechanism by which insoluble lithium in slag was transformed into soluble lithium by salt roasting was proposed using the analysis of XRD and EDS spectra, in which ion exchange occurred between $\mathrm{Na}^{+}$and $\mathrm{Li}^{+}$at a certain temperature.

Received 18th May 2019

Accepted 17th July 2019

DOI: $10.1039 / \mathrm{c} 9 \mathrm{ra03754c}$

rsc.li/rsc-advances

Nevertheless, a big disadvantage of all pyrometallurgical recycling processes for spent LIBs is that lithium is hard to be reduced ${ }^{22}$ due to which lithium is left in the smelting slag phas $^{25}$ with the addition of slag-forming agents such as $\mathrm{CaO}$ and $\mathrm{SiO}_{2} \cdot{ }^{26,27}$ Generally, the slag is directly utilized as an additive in cement manufacturing, which is neither ecological nor resource-saving, especially for lithium. Recently, our research group proposed a strategy of lithium recovery from pyrometallurgical slag (pyro-slag) involving $\mathrm{CaCl}_{2}$ by roasting at high temperatures, in which the evaporation of LiCl from slag was the key to recovery. ${ }^{28}$ However, the relatively high reaction temperature $\left(1000{ }^{\circ} \mathrm{C}\right)$ inevitably led to high energy consumption.

An effective method of salt roasting followed by waterleaching was applied to extract lithium from lepidolite and spodumene, in which the ore was activated at certain temperatures and insoluble lithium was transformed into soluble lithium, which was extracted by water. In 1955, Ellestad and Clarke confirmed that $\mathrm{K}_{2} \mathrm{SO}_{4}$ as an ion exchange reagent can greatly extract lithium from spodumene. ${ }^{29}$ Due to the high cost of $\mathrm{K}_{2} \mathrm{SO}_{4}$, an improved base exchange with $\mathrm{Na}_{2} \mathrm{SO}_{4}$ was introduced by Yan $e t$ al., in which over $90 \%$ lithium from lepidolite was recovered by salt roasting with the mixture of $\mathrm{Na}_{2} \mathrm{SO}_{4}$ and $\mathrm{K}_{2} \mathrm{SO}_{4}$, followed by water leaching. ${ }^{30}$ Salt roasting using $\mathrm{Na}_{2} \mathrm{SO}_{4}$ for lepidolite was subsequently conducted by Luong et al. ${ }^{31}$ Because the main chemical composition of the pyro-slag is very similar to that of lepidolite, if lithium is extracted by water leaching from its slag, the recovery process can be greatly valuable for the cyclic utilization of LIBs.

In this study, the approach of salt roasting and water Beijing, Beijing 100083, PR China.E-mail: zdchang@ustb.edu.cn

${ }^{b}$ Women University Swabi, 23430, KPK, Pakistan

$\dagger$ Electronic supplementary information (ESI) available: See DOI: leaching was employed to recycle lithium from pyro-slag which 
was obtained by the pyrometallurgical treatment of spent LIBs. The factors influencing lithium extraction were investigated and optimized, including roasting and leaching conditions. In addition, the mechanism of lithium recovery was demonstrated by XRD and SEM analyses.

\section{Experimental}

\subsection{Instruments and reagents}

The concentration of lithium in the samples was measured using an atomic absorption spectrophotometer (AAS, AA 6800, Shimadzu, Japan) at a wavelength of $670.8 \mathrm{~nm}$ with a current of $8 \mathrm{~mA}$. The thermochemical properties of the samples were characterized by a thermogravimetric analyzer (TG/SDTA, TGA/ SDTA851 ${ }^{\mathrm{e}}$, Mettler Toledo, Switzerland), in which the mixtures were heated in an air environment from 25 to $1000{ }^{\circ} \mathrm{C}$ at a heating rate of $10{ }^{\circ} \mathrm{C} \mathrm{min}^{-1}$ in an alumina crucible. The data were processed with Mettler Toledo STAR software. The crystalline phases of the samples were analyzed by powder X-ray diffraction (XRD) (D/MAX-RB, Rigaku, Japan) with a $\mathrm{Cu} \mathrm{K \alpha}$ radiation of $\lambda=1.5405 \AA$. The morphologies and element distribution of the samples were determined using a scanning electron microscope (SEM, SU8010, Hitachi, Japan) equipped with energy-dispersive X-ray spectroscopy (EDS).

Lithium oxide $\left(\mathrm{Li}_{2} \mathrm{O}\right.$, analytical grade, $>98.0 \%$ purity, $M_{\mathrm{w}}=$ $\left.29.88 \mathrm{~g} \mathrm{~mol}^{-1}\right)$, calcium oxide (CaO, analytical grade, $M_{\mathrm{w}}=$ $\left.56.077 \mathrm{~g} \mathrm{~mol}^{-1}\right)$, aluminum oxide $\left(\mathrm{Al}_{2} \mathrm{O}_{3}\right.$, analytical grade, $M_{\mathrm{w}}=$ $\left.101.96 \mathrm{~g} \mathrm{~mol}^{-1}\right)$, silica $\left(\mathrm{SiO}_{2}\right.$, analytical grade, $M_{\mathrm{w}}=60.08 \mathrm{~g}$ $\left.\mathrm{mol}^{-1}\right)$, sodium sulfate $\left(\mathrm{Na}_{2} \mathrm{SO}_{4}\right.$, analytical grade, $\geq 99.0 \%$ purity, $M_{\mathrm{w}}=142.04 \mathrm{~g} \mathrm{~mol}^{-1}$ ), and deionizer water (the Laboratory Center of University of Science and Technology Beijing, China) were used.

\subsection{Thermodynamic calculation}

The reactions between three salts $\left(\mathrm{NaCl}, \mathrm{NaNO}_{3}\right.$ and $\left.\mathrm{Na}_{2} \mathrm{SO}_{4}\right)$ and the slag were simulated and further balanced by HSC chemistry 6.0 , which is a computational thermochemical software developed by Outokumpu Oy Information Center. ${ }^{32,33}$ It can calculate enthalpy $(H)$, entropy $(S)$ and Gibbs free energy values $(G)$ for given compounds and temperatures. For the chemical reactions, the Gibbs free energy change $\left(\Delta_{\mathrm{r}} G_{\mathrm{m}}\right)$ and the logarithm of the equilibrium constant $(\log K)$ were calculated using the HSC software. In many cases, it is a very inexpensive and useful tool to find the optimal reaction conditions for experimental investigations. ${ }^{34}$

In this work, the values of $\Delta_{\mathrm{r}} G_{\mathrm{m}}$ and $\log K$ for the related reactions were calculated at $50{ }^{\circ} \mathrm{C}$ intervals from 25 to $1000^{\circ} \mathrm{C}$ at $1 \mathrm{~atm}$ based on the HSC software. According to the $\Delta_{\mathrm{r}} G_{\mathrm{m}}$ and $\log K$ values, the optimal roasting reagent and temperature were subsequently determined.

\subsection{Preparation of simulated pyro-slag}

Using pyrometallurgical treatment for spent LIBs, most of the metals such as $\mathrm{Fe}, \mathrm{Ni}, \mathrm{Cu}$, and $\mathrm{Co}$ in the battery could be recovered as an alloy by carbon reduction roasting. The residues containing aluminum and lithium, which were hard to reduce, were used to produce the building materials by adding slagforming agents, e.g., $\mathrm{CaO}$ and $\mathrm{SiO}_{2}$. The approximate composition of slag could be expressed as $x \mathrm{SiO}_{2} \cdot y \mathrm{CaO} \cdot z \mathrm{Al}_{2} \mathrm{O}_{3} \cdot n \mathrm{Li}_{2} \mathrm{O}$.

Generally, the composition of actual pyro-slag is $20-60 \mathrm{wt} \%$ $\mathrm{SiO}_{2}, 20-35 \mathrm{wt} \% \mathrm{CaO}, 10-30 \mathrm{wt} \% \mathrm{Al}_{2} \mathrm{O}_{3}$ and $0.5-15 \mathrm{wt} \% \mathrm{Li}_{2} \mathrm{O}{ }^{35}$ The intricacy of the actual slag composition makes it hard to be scientifically analyzed. Therefore, a simulated slag containing the dominant components of actual slag such as $\mathrm{SiO}_{2}, \mathrm{CaO}$, $\mathrm{Al}_{2} \mathrm{O}_{3}$ and $\mathrm{Li}_{2} \mathrm{O}$ was prepared. The detailed mass ratio of $\mathrm{SiO}_{2^{-}}$ : $\mathrm{CaO}: \mathrm{Al}_{2} \mathrm{O}_{3}: \mathrm{Li}_{2} \mathrm{O}$ was $50: 35: 12: 3$. The mixture in the graphite crucibles was prepared after grinding and then roasted in a muffle furnace for $2 \mathrm{~h}$ under $1200^{\circ} \mathrm{C}$. After being cooled in air, the as-prepared sintered simulated slag was crushed and further ground.

\subsection{Roasting and leaching procedure}

Two $g$ of simulated slag was mixed with $\mathrm{Na}_{2} \mathrm{SO}_{4}$ at different molar ratios of $\mathrm{Na}_{2} \mathrm{SO}_{4} / \mathrm{Li}(1: 1,2: 1,3: 1$ and $4: 1)$ and then roasted in graphite crucibles at a selected temperature region $\left(500-900{ }^{\circ} \mathrm{C}\right.$ ) from 20 to $120 \mathrm{~min}$. Calcines were cooled to room temperature. Subsequently, the above samples were ground for $20 \mathrm{~min}$ and leached with water at $30-90^{\circ} \mathrm{C}$ for $20-120$ min using water/calcine mass ratios of $10: 1$ to $50: 1$. The liquid-solid phase was separated by filtration and the residue was washed thoroughly with distilled water several times. The leaching solution was analyzed by AAS to determine the concentration of lithium. The formulas for the recovery rate of lithium are expressed as follows:

$$
\begin{gathered}
m_{1}=C_{0} V M_{1} \\
m_{2}=\frac{2 M_{1} m_{0} \omega_{0}}{M_{2}} \\
\text { Recovery rate }=\frac{m_{1}}{m_{2}} \times 100 \%=\frac{C_{0} V M_{2}}{2 m_{0} \omega_{0}} \times 100 \%
\end{gathered}
$$

Here, $m_{0}, m_{1}$ and $m_{2}$ are the masses of the initial slag, lithium in the leaching solution, and lithium in the initial slag, respectively; $C_{0}$ is the lithium concentration in solution, and $V$ is the volume of the solution by water leaching. Furthermore, $M_{1}$ and $M_{2}$ are the molar masses of lithium and $\mathrm{Li}_{2} \mathrm{O}$, and $\omega_{0}$ is the mass fraction of $\mathrm{Li}_{2} \mathrm{O}$ in the initial slag.

\section{Results and discussion}

\subsection{Characterization of simulated slag}

The XRD pattern of simulated slag is shown in Fig. 1. The major peaks matched well with the peaks of $\mathrm{CaSiO}_{3}$ (triclinic, JCPDS file no. 31-0300) and $\mathrm{LiAl}\left(\mathrm{SiO}_{3}\right)_{2}$ ( $\beta$-spodumene, JCPDS file no. 31-0706), indicating that the main components of the simulated pyro-slag were $\mathrm{CaSiO}_{3}(\mathrm{~T})$ and $\mathrm{LiAl}\left(\mathrm{SiO}_{3}\right)_{2}$. A few weak peaks corresponded to the peaks of CaO (JCPDS file no. 48-1467).

\subsection{Selection of roasting reagents}

It is impossible to acquire lithium from initial pyro-slag directly since lithium exists in $\mathrm{LiAl}\left(\mathrm{SiO}_{3}\right)_{2}$, which can hardly be broken. The insoluble lithium can be converted to soluble lithium by salt 


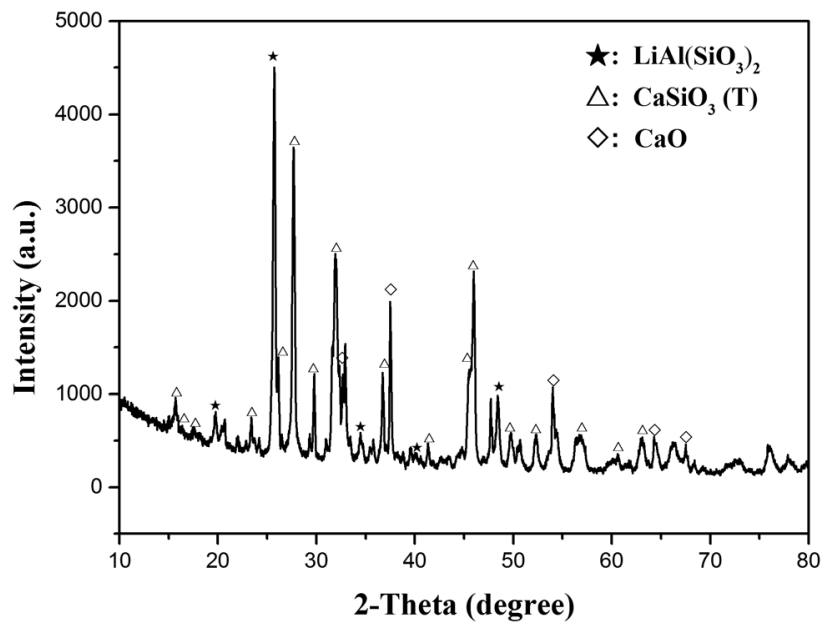

Fig. 1 XRD pattern of simulated slag.

roasting; then, it can be extracted with water, which is used in the process of lithium recovery from an ore. ${ }^{36}$ To investigate whether the pyro-slag exhibits a similar behavior to that of a lithium ore, three reactions between the $\mathrm{NaCl}, \mathrm{NaNO}_{3}$ and $\mathrm{Na}_{2} \mathrm{SO}_{4}$ salts and $\mathrm{LiAl}\left(\mathrm{SiO}_{3}\right)_{2}$ were simulated; the thermodynamic parameters such as $\Delta_{\mathrm{r}} G_{\mathrm{m}}$ and $\log K$ were calculated using the HSC software. The possible reactions of $\mathrm{NaCl}, \mathrm{NaNO}_{3}$ and $\mathrm{Na}_{2} \mathrm{SO}_{4}$ with $\mathrm{LiAl}\left(\mathrm{SiO}_{3}\right)_{2}$ during roasting can be expressed as follows:

$$
\begin{gathered}
\mathrm{NaCl}+\mathrm{LiAl}\left(\mathrm{SiO}_{3}\right)_{2}=\mathrm{NaAl}\left(\mathrm{SiO}_{3}\right)_{2}+\mathrm{LiCl} \\
\mathrm{NaNO}_{3}+\mathrm{LiAl}\left(\mathrm{SiO}_{3}\right)_{2}=\mathrm{NaAl}\left(\mathrm{SiO}_{3}\right)_{2}+\mathrm{LiNO}_{3} \\
\mathrm{Na}_{2} \mathrm{SO}_{4}+\mathrm{LiAl}\left(\mathrm{SiO}_{3}\right)_{2}=\mathrm{NaAl}\left(\mathrm{SiO}_{3}\right)_{2}+\mathrm{NaLiSO}_{4}
\end{gathered}
$$

The results obtained are plotted in Fig. 2. It can be seen that $\Delta_{\mathrm{r}} G_{\mathrm{m}}$ is positive and $\log K$ is negative within the temperature range (Fig. 2a), which suggest that the reaction for extracting lithium with $\mathrm{NaCl}$ cannot occur spontaneously. The relevant values of $\Delta_{\mathrm{r}} G_{\mathrm{m}}$ and $\log K$ calculated by eqn (5) are depicted in Fig. 2b. The value for $\Delta_{\mathrm{r}} G_{\mathrm{m}}$ was positive and that for $\log K$ was negative, indicating that $\mathrm{NaNO}_{3}$ could not exchange lithium in the roasting process. The trend graphs of $\Delta_{\mathrm{r}} G_{\mathrm{m}}$ and $\log K$ between $\mathrm{LiAl}\left(\mathrm{SiO}_{3}\right)_{2}$ and $\mathrm{Na}_{2} \mathrm{SO}_{4}$. are shown in Fig. $2 \mathrm{c} ; \Delta_{\mathrm{r}} G_{\mathrm{m}}$ is positive from 25 to $525^{\circ} \mathrm{C}$, and $\log K$ is less than zero within this range, which indicate that the reaction cannot occur spontaneously at $25-525{ }^{\circ} \mathrm{C}$. Interestingly, $\Delta_{\mathrm{r}} G_{\mathrm{m}}$ was negative and the corresponding $\log K$ value was positive after $525{ }^{\circ} \mathrm{C}$, which indicated that the reaction could occur spontaneously when the temperature increased to $525^{\circ} \mathrm{C}$. Accordingly, $\mathrm{Na}_{2} \mathrm{SO}_{4}$ was assumed to be a suitable reagent for roasting.

To further prove the reaction possibility of $\mathrm{Na}_{2} \mathrm{SO}_{4}$ and slag, the characteristics of the mixture of slag and $\mathrm{Na}_{2} \mathrm{SO}_{4}$ at a molar ratio of $1: 3$ were studied by thermogravimetric analysis and simultaneous differential thermal analysis (TGA-SDTA). As shown in Fig. 3, three significant endothermic processes in the SDTA curve are observed at $25-1000^{\circ} \mathrm{C}$. For the first process, the endothermic peak was located at approximately $40{ }^{\circ} \mathrm{C}$ and a weight increase was observed from the TGA curve, which could be ascribed to the water absorption behavior of slag. In the second endothermic process, the endothermic peak was at about $250{ }^{\circ} \mathrm{C}$. There was no weight loss observed from the TGA curve, which was attributed to the phase transition of $\mathrm{Na}_{2} \mathrm{SO}_{4}$ to rhombic $\mathrm{Na}_{2} \mathrm{SO}_{4}$. The third endothermic process occurred from 470 to $1000{ }^{\circ} \mathrm{C}$, where the TGA curve showed no change, indicating that the reaction between $\mathrm{Na}_{2} \mathrm{SO}_{4}$ and slag may occur at this stage. Therefore, $\mathrm{Na}_{2} \mathrm{SO}_{4}$ was considered as the optimized roasting reagent and the temperature of $470-1000{ }^{\circ} \mathrm{C}$ was selected as the best roasting range for lithium extraction, which was in accordance with HSC thermodynamic calculations.

Here, the technological process of roasting and water leaching was employed to discuss the possibility of recovering lithium from pyro-slag. The flow sheet is shown in Fig. 4.

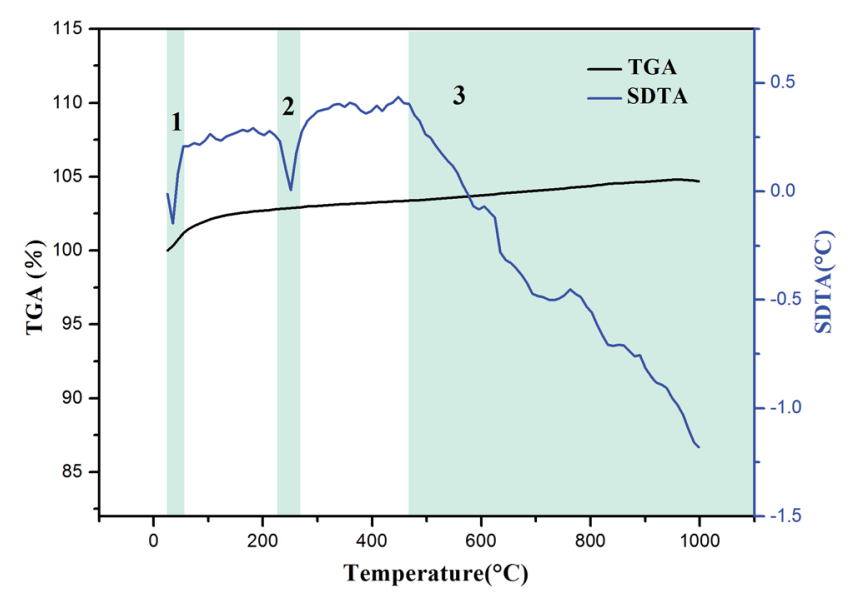

Fig. 3 TGA-SDTA curves of the mixture of slag and $\mathrm{Na}_{2} \mathrm{SO}_{4}$.
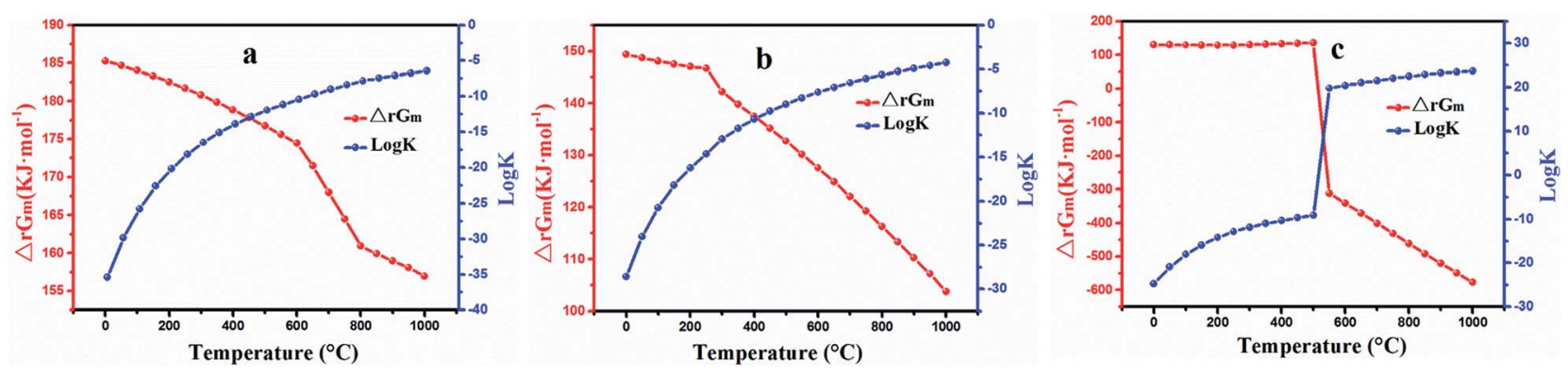

Fig. 2 Calculated $\Delta_{r} G_{m}$ and $\log K$ for the reactions as a function of temperature: (a) eqn (4), (b) eqn (5) and (c) eqn (6). 


\subsection{Roasting procedure}

For the roasting procedure, the lithium extraction efficiency was significantly influenced by several operational parameters such as the roasting temperature, roasting duration and molar ratio of $\mathrm{Na}_{2} \mathrm{SO}_{4} / \mathrm{Li}$. In order to balance the roasting efficiency and cost, the optimization of the roasting conditions is necessary. The leaching conditions were fixed as follows: liquid-to-solid (L/ S) mass ratio of $20: 1$, leaching temperature of $25{ }^{\circ} \mathrm{C}$ and leaching time of $60 \mathrm{~min}$.

3.3.1 Effect of roasting temperature on the extraction efficiency of lithium. Since the HSC modeling and TGA-SDTA curve showed that the reaction of slag and $\mathrm{Na}_{2} \mathrm{SO}_{4}$ started at about $500{ }^{\circ} \mathrm{C}$, a range of roasting temperatures from 500 to $900{ }^{\circ} \mathrm{C}$ were chosen for investigation. The roasting time (60 $\mathrm{min})$ remained constant. The effect of roasting temperature at different molar ratios of $\mathrm{Na}_{2} \mathrm{SO}_{4} / \mathrm{Li}(1: 1,2: 1,3: 1$ and $4: 1)$ on the lithium extraction efficiency was investigated. The results are shown in Fig. 5 (the lithium concentration data are given in Table $\mathrm{S} 1 \dagger$ ), which indicate that temperature has a considerable influence on lithium extraction. The extraction rate of lithium increased first and then decreased as the annealing temperature increased. The best roasting temperature was $800{ }^{\circ} \mathrm{C}$ at each ratio. As the molar ratio of $\mathrm{Na}_{2} \mathrm{SO}_{4} / \mathrm{Li}$ increased from $1: 1$ to $3: 1$, the lithium extraction efficiency increased with the increase in the $\mathrm{Na}_{2} \mathrm{SO}_{4} / \mathrm{Li}$ molar ratios at the same temperature.

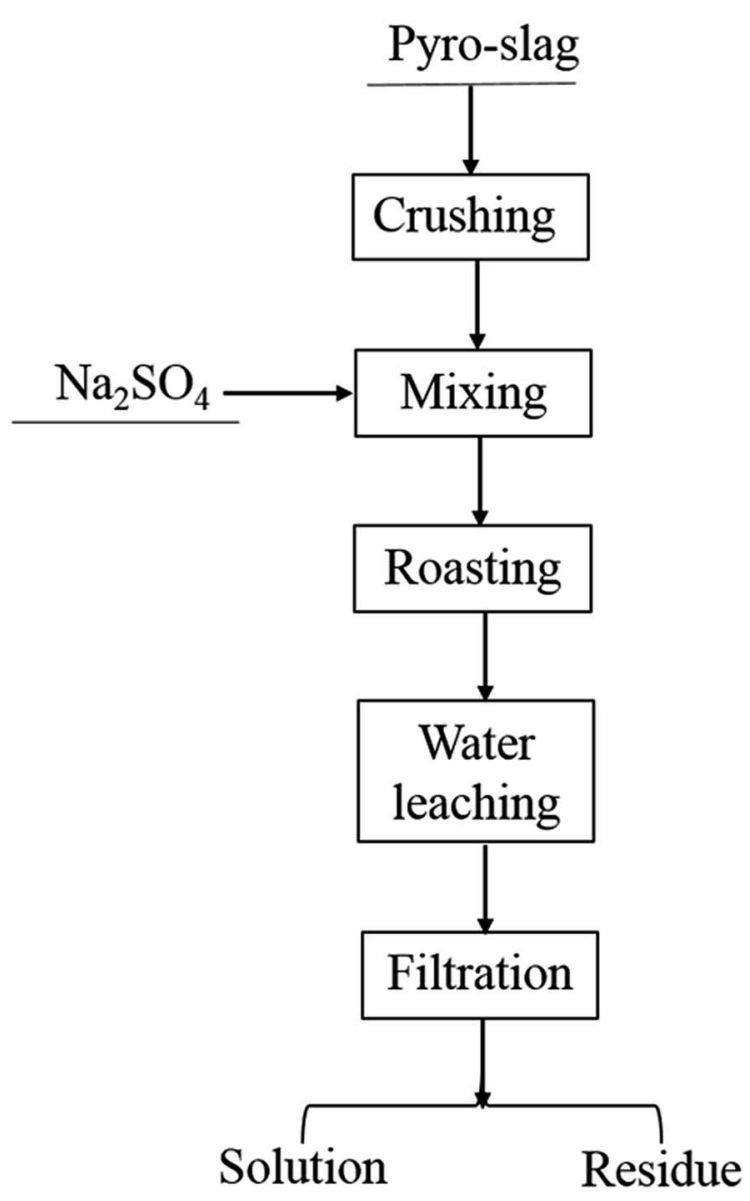

Fig. 4 Flow sheet for the roasting-leaching process.

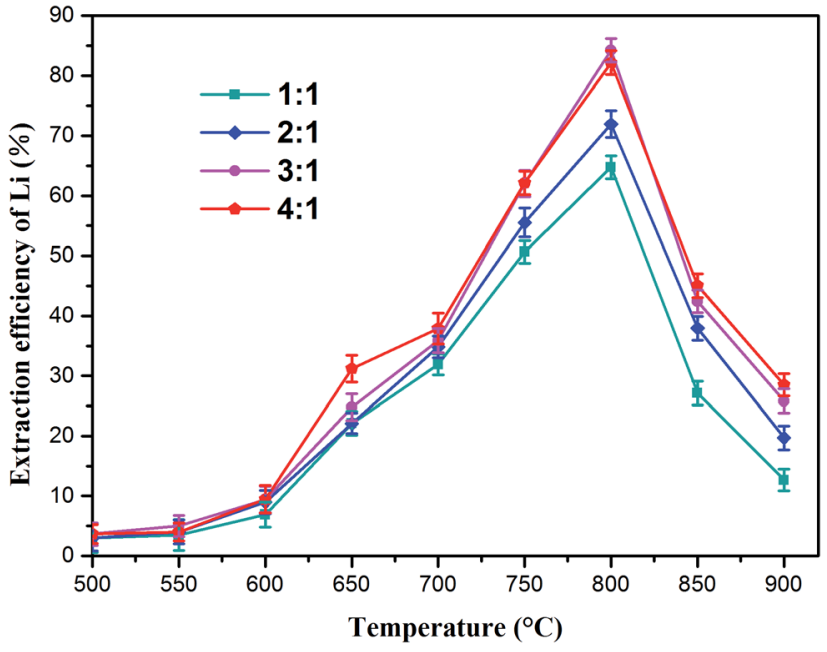

Fig. 5 Effect of roasting temperature on the extraction efficiency of lithium.

However, excess $\mathrm{Na}_{2} \mathrm{SO}_{4}(4: 1)$ had a slight effect on the extraction of lithium within the given temperature range. When the $\mathrm{Na}_{2} \mathrm{SO}_{4} / \mathrm{Li}$ molar ratio of $3: 1$ was used, the lithium extraction reached a maximum $(84.2 \%)$ at $800{ }^{\circ} \mathrm{C}$. Nevertheless, higher temperatures $\left(800-900{ }^{\circ} \mathrm{C}\right)$ led to reduction in the leachable lithium compounds. This indicated that the reacting ability between $\mathrm{Na}_{2} \mathrm{SO}_{4}$ and slag weakened above $800{ }^{\circ} \mathrm{C}$, leading to reduction in soluble lithium.

$\mathrm{XRD}$ analysis was performed to evaluate the components of the roasted slag. The XRD patterns of the slag and $\mathrm{Na}_{2} \mathrm{SO}_{4}$ after roasting with a molar ratio of $\mathrm{Na}_{2} \mathrm{SO}_{4} / \mathrm{Li}$ of $3: 1$ at different temperatures (700-900 ${ }^{\circ} \mathrm{C}$ ) are shown in Fig. 6 . When the roasting temperature was $700{ }^{\circ} \mathrm{C}$, the main components of the sample were $\mathrm{LiNaSO}_{4}$ (JCPDS file no. 20-0638) and $\mathrm{CaSiO}_{3}(\mathrm{~T})$. In addition, small peaks for $\mathrm{Ca}_{2} \mathrm{SiO}_{4}$ appeared, which were due to the reaction between $\mathrm{CaSiO}_{3}$ and $\mathrm{CaO}$ in the initial slag. It should be noted that the diffraction peaks of $\mathrm{CaSiO}_{3}(\mathrm{~T})$ became

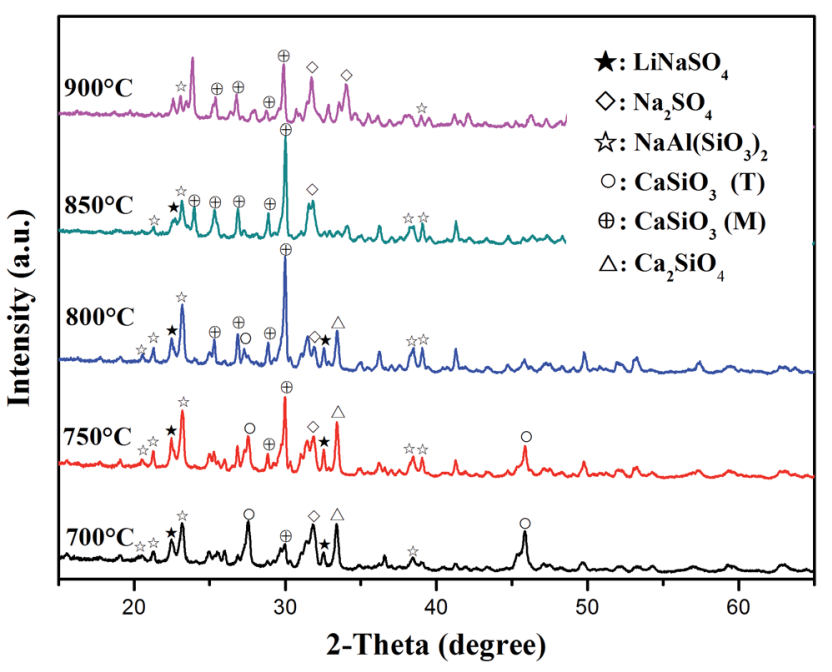

Fig. 6 XRD patterns of samples calcined at different temperatures for $60 \mathrm{~min}$. 
weaker and the peaks of $\mathrm{CaSiO}_{3}$ (monoclinic, JCPDS file no. 270088) appeared as the temperature increased to $750{ }^{\circ} \mathrm{C}$. This behavior may be related to the phase transition of $\mathrm{CaSiO}_{3}(\mathrm{~T})$ in slag at high temperatures. The peaks of $\mathrm{LiNaSO}_{4}$ and $\mathrm{CaSiO}_{3}(\mathrm{M})$ became stronger at $800{ }^{\circ} \mathrm{C}$. Meanwhile, the peaks of $\mathrm{CaSiO}_{3}(\mathrm{~T})$ disappeared due to the complete phase transformation of $\mathrm{CaSiO}_{3}(\mathrm{~T})$. When the roasting temperature increased to $850{ }^{\circ} \mathrm{C}$, the diffraction peaks of $\mathrm{LiNaSO}_{4}$ became weaker and the peaks of $\mathrm{Na}_{2} \mathrm{SO}_{4}$ (JCPDS file no. 24-1132) appeared. The main phases were $\mathrm{CaSiO}_{3}(\mathrm{M})$ and $\mathrm{Na}_{2} \mathrm{SO}_{4}$ containing a small amount of $\mathrm{LiNaSO}_{4}$ at this temperature. As the temperature increased to $900{ }^{\circ} \mathrm{C}$, the diffraction peaks of $\mathrm{LiNaSO}_{4}$ almost disappeared and the peaks of $\mathrm{Na}_{2} \mathrm{SO}_{4}$ obviously increased, which can be attributed to the weaker reactivity of $\mathrm{Na}_{2} \mathrm{SO}_{4}$ at $800-900{ }^{\circ} \mathrm{C}$. The appearance of $\mathrm{LiNaSO}_{4}$ in the roasted products indicated that the insoluble lithium in the original slag was transformed to a soluble structure during the roasting process. Accordingly, water leaching is an effective way to extract lithium from roasted products. Moreover, the trend for the peak intensity of $\mathrm{LiNaSO}_{4}$ with temperature was positively associated with the change in the lithium extraction efficiency (Fig. 5).

The SEM image of the initial slag after being reground by a planetary ball mill is shown in Fig. 7a. It can be seen that the particles exhibit a smooth surface with diameters from 1 to $5 \mu \mathrm{m}$. Fig. 7b shows the SEM image of the calcined mixture of pyro-slag and $\mathrm{Na}_{2} \mathrm{SO}_{4}$. Clearly, the particle size after sodium roasting was smaller than that of the initial slag. Moreover, the uneven and porous nature of the surface was observed after calcination.

3.3.2 Effect of roasting time on the extraction efficiency of lithium. The effect of roasting time on the lithium recovery efficiency with a fixed molar ratio of $\mathrm{Na}_{2} \mathrm{SO}_{4} / \mathrm{Li}(3: 1)$ at various temperatures $\left(750{ }^{\circ} \mathrm{C}, 800{ }^{\circ} \mathrm{C}\right.$ and $\left.850{ }^{\circ} \mathrm{C}\right)$ is shown in Fig. 8 and the lithium concentration data are shown in Table S2. $\dagger$ The curves for the lithium extraction efficiency showed almost the same trends at different roasting temperatures. As the roasting time increased from 20 to $60 \mathrm{~min}$, the efficiency of lithium extraction had a positive correlation with the roasting time. However, the opposite trend appeared at 60-120 min. The lithium recovery rate reached a maximum of $84.2 \%$ under the following conditions: roasting time of $60 \mathrm{~min}$ and roasting temperature of $800{ }^{\circ} \mathrm{C}$. Therefore, the roasting time was set at $60 \mathrm{~min}$ in the subsequent experiments.

\subsection{Water leaching procedure}

To investigate the effect of leaching temperature, leaching time and L/S mass ratio on the lithium extraction efficiency,
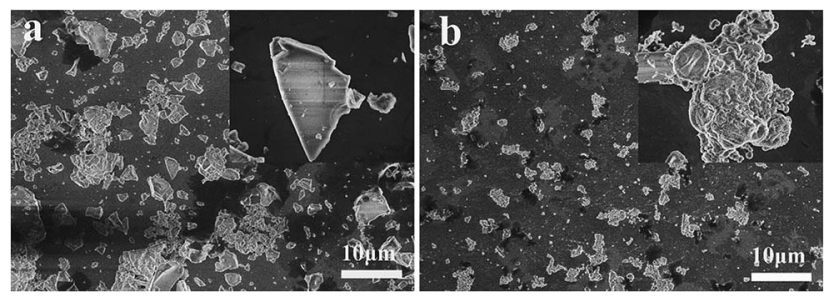

Fig. 7 SEM images of the slag/ $\mathrm{Na}_{2} \mathrm{SO}_{4}$ mixture (a) before and (b) after roasting.

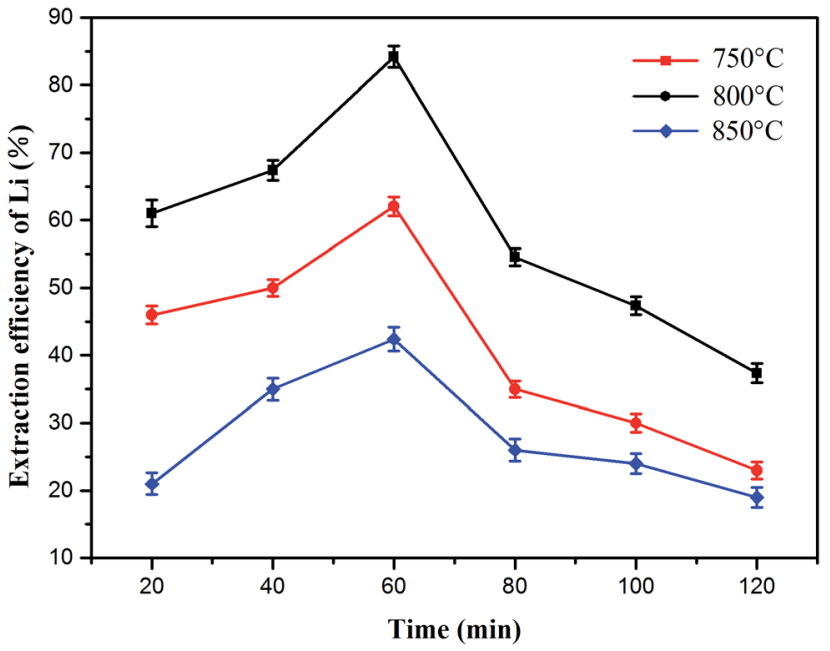

Fig. 8 Effect of roasting time on leaching efficiency of lithium at different roasting temperatures $\left(\mathrm{Na}_{2} \mathrm{SO}_{4} / \mathrm{Li}\right.$ molar ratio of $\left.3: 1\right)$.

typical leaching tests at different conditions were conducted. The conditions for the roasting product were fixed: $\mathrm{Na}_{2} \mathrm{SO}_{4} / \mathrm{Li}$ molar ratio of $3: 1$ and roasting temperature of $800{ }^{\circ} \mathrm{C}$ for $60 \mathrm{~min}$.

3.4.1 Effect of the leaching temperature and duration on the extraction efficiency of lithium. The effect of the leaching temperature at $30-90{ }^{\circ} \mathrm{C}$ on the lithium extraction efficiency was investigated. Here, the L/S mass ratio (20:1) and leaching time (60 min) were fixed. As shown in Fig. 9 (lithium concentration data are given in Table S $3 \dagger$ ), the results reveal that the leaching temperature has considerable influence on lithium recovery. The lithium extraction efficiency increased from 84.86 to $90.89 \%$ in the experimental temperature range. Here, $70{ }^{\circ} \mathrm{C}$ was recommended as the optimum leaching temperature for energy consumption.

Additionally, the effect of leaching time was investigated from 20 to $120 \mathrm{~min}$; the leaching temperature $\left(70{ }^{\circ} \mathrm{C}\right)$ and $\mathrm{L} / \mathrm{S}$

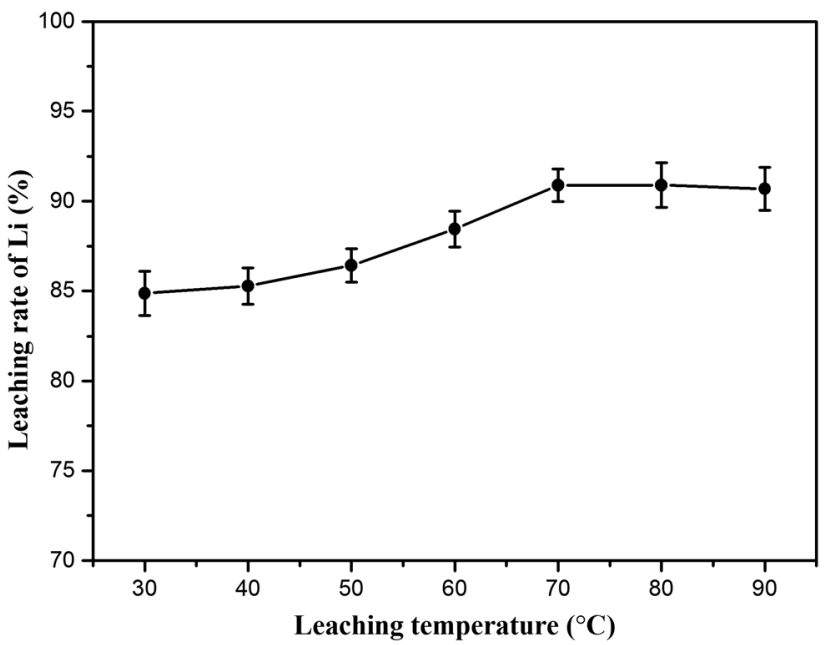

Fig. 9 Effect of the leaching temperature on the leaching efficiency of lithium. 
mass ratio $(20: 1)$ were fixed. The lithium extraction was positively correlated with the leaching time, as shown in Fig. 10. It was clear that the leaching time of $80 \mathrm{~min}$ resulted in the maximum recovery of lithium, in which $91.98 \%$ of lithium was recovered after leaching (lithium concentration data are given in Table $\mathrm{S} 4 \dagger$ ).

3.4.2 Effect of the $\mathrm{L} / \mathrm{S}$ mass ratio on the extraction of lithium. The effect of the mass ratios of $\mathrm{L} / \mathrm{S}$ was investigated from $10: 1$ to $50: 1$ at $70{ }^{\circ} \mathrm{C}$ for $80 \mathrm{~min}$. The results are plotted in Fig. 11 with the lithium concentration data given in Table S5. $\dagger$ The lithium extraction efficiency showed slight increase as the mass ratio of $\mathrm{L} / \mathrm{S}$ increased; when the ratio was $30: 1$, the extraction efficiency of lithium increased to $93.62 \%$ and remained stable at the subsequent ratios. Since a higher L/S ratio in the water leaching process indicates that more energy is consumed in the subsequent liquid recovery, the L/S ratio of $30: 1$ seemed to be advisable.

For the water-leaching process, the optimal conditions were experimentally determined to be $70{ }^{\circ} \mathrm{C}$ for $80 \mathrm{~min}$ using a liquidto-solid (L/S) mass ratio of $30: 1$ to yield a maximum of $93.62 \%$ lithium recovery.

\subsection{Recovery mechanism}

To analyze the mechanism of lithium extraction by $\mathrm{Na}_{2} \mathrm{SO}_{4}$, the phase analysis of the leaching solution and leached residue is shown in Fig. 12. The XRD pattern of the product by the evaporation of the leaching solution is depicted in Fig. 12a. The peaks of $\mathrm{Na}_{2} \mathrm{SO}_{4}, \mathrm{LiNaSO}_{4}$ and $3 \mathrm{LiOH} \cdot \mathrm{Li}_{2} \mathrm{SO}_{4}$ are observed, indicating that insoluble lithium in slag has been transformed into soluble lithium compounds by roasting. The peaks of $\mathrm{NaAl}\left(\mathrm{SiO}_{3}\right)_{2}$ (JCPDS file no. 46-0012) and $\mathrm{CaSiO}_{3}(\mathrm{M})$ in the leached residue were observed (Fig. 12b). It was obvious that $\mathrm{CaSiO}_{3}$ had a crystal phase transition from triclinic in the initial slag to monoclinic in the leached residue. The peaks of $\mathrm{LiAl}\left(\mathrm{SiO}_{3}\right)_{2}$ in the initial slag disappeared completely and those for $\mathrm{NaAl}\left(\mathrm{SiO}_{3}\right)_{2}$ appeared, indicating that sodium in $\mathrm{Na}_{2} \mathrm{SO}_{4}$ was fixed in the solid phase by roasting.

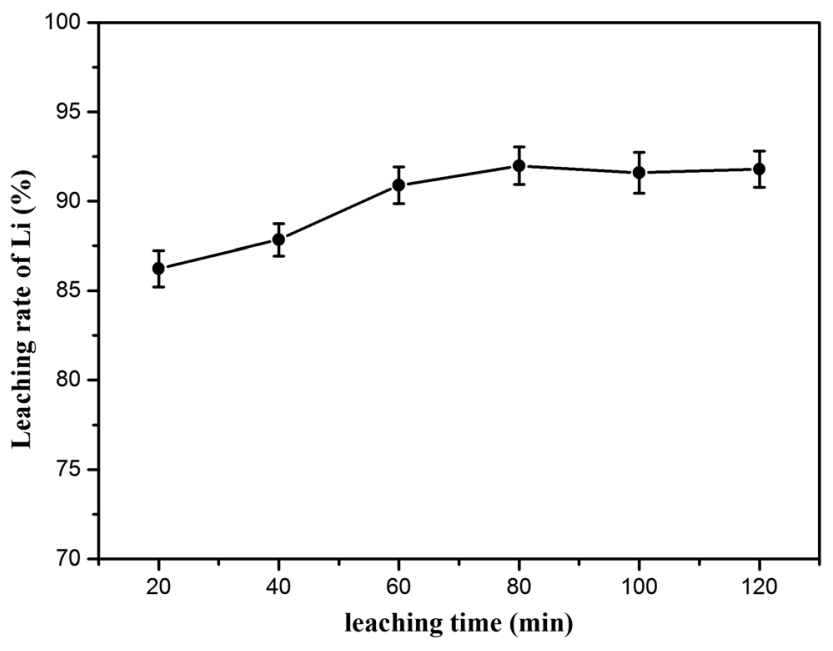

Fig. 10 Effect of leaching time on leaching efficiency of lithium.

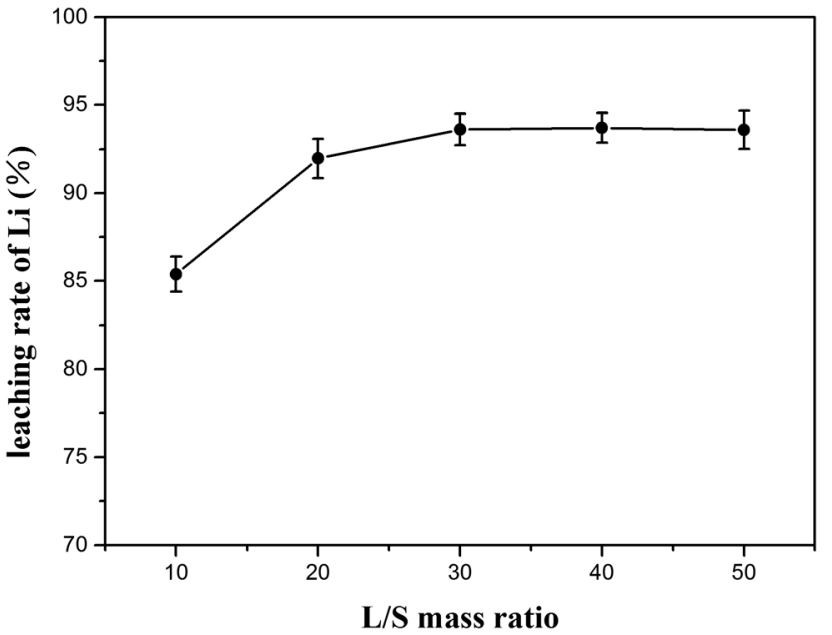

Fig. 11 Effect of the L/S mass ratio on the leaching efficiency of lithium.

Fig. 13a-f show the SEM images of the leached residue and the corresponding EDS mapping. From Fig. 13e and f, it can be observed that the distribution of $\mathrm{Si}$ and $\mathrm{O}$ is homogeneous in the whole imaging area of the corresponding SEM image. Additionally, the Na and Al elements are mainly distributed in the bottom area of the images, as shown in Fig. 13b and c, indicating the existence of $\mathrm{NaAl}\left(\mathrm{SiO}_{3}\right)_{2}$. The uneven and porous surface of $\mathrm{NaAl}\left(\mathrm{SiO}_{3}\right)_{2}$ is observed in Fig. 13a. Furthermore, the rod-like morphology of the Ca element is observed in Fig. 13d, which corresponds to the same morphology in Fig. 13a. The observation indicates the $\mathrm{CaSiO}_{3}$ (M) in leached residue presents a rod-like morphology. Based on the above analysis, it was concluded that $\mathrm{NaAl}\left(\mathrm{SiO}_{3}\right)_{2}$ and $\mathrm{CaSiO}_{3}(\mathrm{M})$ existed in the leached residue simultaneously, which was in accordance with the results of XRD in Fig. 12a.

The chemical composition of the leached residue was analyzed by EDS. As shown in Fig. 14, the elements of $\mathrm{O}, \mathrm{Na}, \mathrm{Al}$, $\mathrm{Si}, \mathrm{S}$ and $\mathrm{Ca}$ are detected on the surface. The mass fraction and the normalized molecular numbers of each element are listed in the inset of Fig. 14. It is worth noting that the presence of S in the sample could be attributed to the adsorption of excess $\mathrm{Na}_{2} \mathrm{SO}_{4}$ on porous $\mathrm{NaAl}\left(\mathrm{SiO}_{3}\right)_{2}$, which was hard to leach. Based on the comparison of the results after normalization for different elements, the results revealed that the stoichiometric
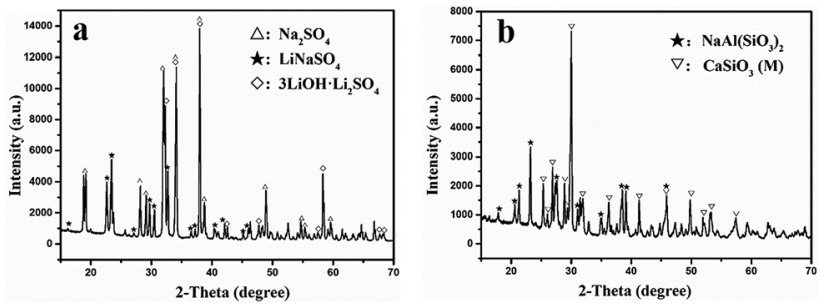

Fig. 12 XRD patterns of the leaching solution (a) and leached residue (b). 

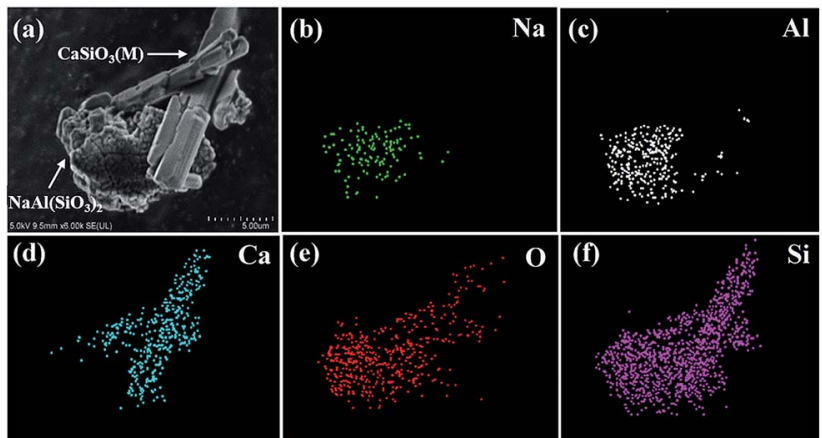

Fig. 13 SEM image (a) and element mapping images of leached residue $(b-f)$.

\begin{tabular}{|c|c|c|c|}
\hline . & Elements & $\mathbf{w t} \%$ & Normalized values \\
\hline & o & 55.491 & 12.57 \\
\hline & $\mathrm{Na}$ & 7.756 & 1.22 \\
\hline & Al & 7.449 & 1 \\
\hline \multirow{3}{*}{ 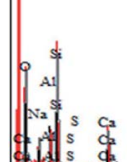 } & $\mathrm{Si}$ & 23.072 & 2.99 \\
\hline & $\mathbf{s}$ & 0.237 & 0.027 \\
\hline & $\mathrm{Ca}$ & 12.901 & 1.17 \\
\hline
\end{tabular}

Fig. 14 EDS spectrum of the leached residue.
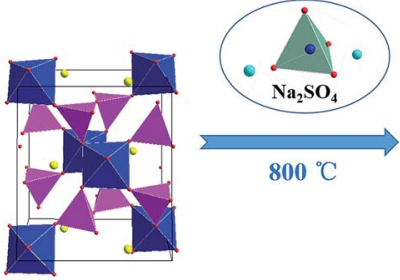

$\mathrm{LiAl}\left(\mathrm{SiO}_{3}\right)_{2}$

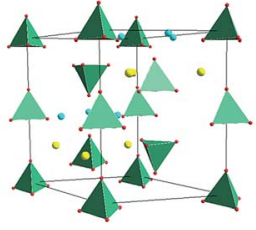

$\mathrm{LiNaSO}_{4}$

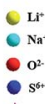

Si-O polyhedron Al-O polyhedron 4 s-o polyhedron
Fig. 15 Schematic of insoluble lithium conversion into soluble lithium with the additive $\mathrm{Na}_{2} \mathrm{SO}_{4}$ by roasting.

proportion of $\mathrm{O}, \mathrm{Na}, \mathrm{Al}, \mathrm{Si}, \mathrm{S}$ and $\mathrm{Ca}$ was in accordance with the composition of $\mathrm{NaAl}\left(\mathrm{SiO}_{3}\right)_{2}, \mathrm{CaSiO}_{3}(\mathrm{M})$ and $\mathrm{Na}_{2} \mathrm{SO}_{4}$, which was consistent with the XRD and SEM results.

According to above analysis, an ion exchange mechanism was proposed for the process of salt roasting, where the insoluble lithium in initial pyro-slag was exchanged with $\mathrm{Na}^{+}$to convert to soluble lithium and was then recovered by water. The schematic diagram of the ion exchange process for lithium is shown in Fig. 15.

\section{Conclusion}

In conclusion, the strategy of recycling lithium from the simulated pyro-slag of spent LIBs by salt roasting and water leaching was studied. The main components of the simulated slag used in this work were $\mathrm{LiAl}\left(\mathrm{SiO}_{3}\right)_{2}$ and $\mathrm{CaSiO}_{3} \cdot \mathrm{Na}_{2} \mathrm{SO}_{4}$ was optimized as the proper sodium roasting reagent compared to $\mathrm{NaCl}$ and $\mathrm{NaNO}_{3}$. When the slag and $\mathrm{Na}_{2} \mathrm{SO}_{4}$ were mixed with an $\mathrm{Na}_{2} \mathrm{SO}_{4} /$ Li molar ratio of $3: 1$ and calcined at $800{ }^{\circ} \mathrm{C}$ for $60 \mathrm{~min}$ with water leaching at $70{ }^{\circ} \mathrm{C}$ for $80 \mathrm{~min}$ and a mass ratio of $\mathrm{L} / \mathrm{S}$ of $30: 1$, the lithium recovery rate reached $93.62 \%$. Further research suggested that insoluble lithium in slag was transformed into soluble lithium by ion exchange at high temperatures.

\section{Conflicts of interest}

There are no conflicts of interest to declare.

\section{Acknowledgements}

This work was financially supported by the National Natural Science Foundation of China [21276022].

\section{References}

1 Q. Meng, Y. Zhang and P. Dong, Waste Manag., 2017, 64, 214218.

2 X. Zeng, J. Li and L. Liu, Renewable Sustainable Energy Rev., 2015, 52, 1759-1767.

3 N. Bahaloo-Horeh and S. M. Mousavi, Waste Manag., 2017, 60, 666-679.

4 V. T. Luong, D. J. Kang, J. W. An, D. A. Dao, M. J. Kim and T. Tran, Hydrometallurgy, 2014, 141, 8-16.

5 S. Manzetti and F. Mariasiu, Renewable Sustainable Energy Rev., 2015, 51, 1004-1012.

6 B. Huang, Z. Pan, X. Su and L. An, J. Power Sources, 2018, 399, 274-286.

7 B. Swain, Sep. Purif. Technol., 2017, 172, 388-403.

8 T. Hoshino, Fusion Eng. Des., 2013, 88, 2956-2959.

9 K. Richa, C. W. Babbitt, G. Gaustad and X. Wang, Resour., Conserv. Recycl., 2014, 83, 63-76.

10 L. Gaines, Sustainable Mater. Technol., 2014, 1, 2-7.

11 G. H. Broadbent, D. Drozdzewski and G. Metternicht, Geography Compass, 2018, 12, e12358.

12 X. Zhang, L. Li, E. Fan, Q. Xue, Y. Bian, F. Wu and R. Chen, Chem. Soc. Rev., 2018, 47, 7239-7302.

13 H. Li, S. Xing, Y. Liu, F. Li, H. Guo and G. Kuang, ACS Sustainable Chem. Eng., 2017, 5, 8017-8024.

14 G. Nayaka, J. Manjanna, K. Pai, R. Vadavi, S. Keny and V. Tripathi, Hydrometallurgy, 2015, 151, 73-77.

15 G. Nayaka, K. Pai, G. Santhosh and J. Manjanna, Hydrometallurgy, 2016, 161, 54-57.

16 W. Liu, T. Yang, D. Zhang, L. Chen and Y. Liu, JOM, 2014, 66, 1694-1700.

17 T. Tirronen, D. Sukhomlinov, H. O'Brien, P. Taskinen and M. Lundström, J. Cleaner Prod., 2017, 168, 399-409.

18 W. Lv, Z. Wang, H. Cao, Y. Sun, Y. Zhang and Z. Sun, ACS Sustainable Chem. Eng., 2018, 6, 1504-1521. 
19 G.-x. Ren, S.-w. Xiao, M.-q. Xie, P. Bing, C. Jian, F.-g. Wang and X. Xing, Trans. Nonferrous Met. Soc. China, 2017, 27, 450-456.

20 S. Xiao, G. Ren, M. Xie, B. Pan, Y. Fan, F. Wang and X. Xia, Journal of Sustainable Metallurgy, 2017, 3, 703-710.

21 C. W. Purnomo, E. P. Kesuma, I. Perdana and M. Aziz, Waste Manag., 2018, 79, 454-461.

22 T. Georgi-Maschler, B. Friedrich, R. Weyhe, H. Heegn and M. Rutz, J. Power Sources, 2012, 207, 173-182.

23 A. Chagnes and J. Swiatowska, Lithium process chemistry: Resources, extraction, batteries, and recycling, Elsevier, 2015.

24 S. Al-Thyabat, T. Nakamura, E. Shibata and A. Iizuka, Miner. Eng., 2013, 45, 4-17.

25 Y. Chen, N. Liu, F. Hu, L. Ye, Y. Xi and S. Yang, Waste Manag., 2018, 75, 469-476.

26 S. Ziemann, M. Weil and L. Schebek, Resour., Conserv. Recycl., 2012, 63, 26-34.

27 K. Karmazínová, T. Kazda and K. Jandova, ECS Trans., 2017, 81, 255-260.
28 H. Dang, B. Wang, Z. Chang, X. Wu, J. Feng, H. Zhou, W. Li and C. Sun, ACS Sustainable Chem. Eng., 2018, 6, 1316013167.

29 R. B. Ellestad and F. F. Clarke, Extraction of lithium from its ores, Min. Eng., 1955, 7, 1045-1047.

30 Q. Yan, X. Li, Z. Wang, X. Wu, J. Wang, H. Guo, Q. Hu and W. Peng, Int. J. Miner. Process., 2012, 110, 1-5.

31 V. T. Luong, D. J. Kang, J. W. An, M. J. Kim and T. Tran, Hydrometallurgy, 2013, 134, 54-61.

32 M. B. Guerrero, J. S. Gutiérrez, M. M. Zaragoza, A. L. Ortiz and V. Collins-Martínez, Int. J. Hydrogen Energy, 2016, 41, 23232-23237.

33 A. Roine, HSC 6.0 Chemistry. Chemical reactions and Equilibrium software with extensive thermochemical database and Flowsheet simulation, Outokumpu Research Oy Information Center, Pori, 2006.

34 L. I. Barbosa, J. A. González and M. del Carmen Ruiz, Thermochim. Acta, 2015, 605, 63-67.

35 D. Cheret and S. Santen, Battery recycling, US Pat. US7169206A1, January 30, 2007.

36 B. Swain, Sep. Purif. Technol., 2017, 172, 388-403. 